\title{
Using Serious Games and Video Materials in Clinical Training in Nursing and Midwifery Education
}

\author{
https://doi.org/10.3991/ijet.v16i16.23455 \\ Galya Georgieva-Tsaneva ${ }^{1}\left({ }^{-}\right)$, Ivanichka Serbezova ${ }^{2}$ \\ ${ }^{1}$ Bulgarian Academy of Sciences, Sofia, Bulgaria \\ ${ }^{2}$ Angel Kanchev University, Ruse, Bulgaria \\ galicaneva@abv.bg
}

\begin{abstract}
The article presents the serious educational games and video materials (video algorithms) as a means to improve the perception and increase the quality of medical students and the health care students (specialties Nurse and midwife) in higher universities in Bulgaria. The issue of creating models of serious educational games is considered. A serious educational game created with the help of the Kahoot learning platform is presented. The introduction of new technological innovations in the educational process is an important step towards the modernization of the education of today's generation of students. According to a study conducted among students, serious games and video algorithms are effective means of raising the level of education of future Nurses and Midwives. Along with traditional education, they contribute to the formation of highly effective knowledge, skills, competencies, and the acquisition of professional qualities.
\end{abstract}

Keywords—-serious educational games, health care, medical education, nurse, midwife

\section{$1 \quad$ Introduction}

Today, video games are an integral part of modern life and serve primarily for entertainment, unloading from work, school, the world around us, and the norms of behavior [1]. Esposito [2] defines them as: "a game which we play thanks to an audiovisual apparatus and which can be based on a story". According to [3]: "games consist of goals and rules. Players should comply with the rules in order to achieve the goals." Video games are very popular [4] and have over 2 billion users worldwide. The other type of games serve to achieve pre-set useful goals, focus on the formation of professional knowledge, skills, and competencies, and are called serious games [5, 6, 7]. Serious games can be used for training, for the presentation of physical exercises, in trade, medicine, business, for military purposes. Serious games are increasingly becoming a factor in learning, a modern method based on new technologies. Serious games engage the learner in the learning process, lead to an increase in his motivation and increase the student's success. Today's generation uses modern communication technologies on a daily basis and this is a prerequisite for the accessibility of serious games and their 
rapid entry into the learning process. In serious educational games, an innovative, interactive approach is applied in presenting and mastering the learning material, in which learners acquire knowledge and skills to solve problems, communicate, make decisions, work in a team and develop useful social skills.

Serious games created for the purposes of medical education have the potential to be used in the development of professionals in the professional field of "Health Care". Traditional training with listening is proving increasingly ineffective today. Modern students show good mastery of the material when using modern teaching methods, which include learning by doing things. Thus, the effectiveness of the training of students in the professional field of "Health Care" can be increased by including in the training of innovative methods such as the use of serious educational games, video materials, and computer simulations.

The process of designing serious games is a challenge, as there are different types of games and several requirements for them, which are constantly growing. The process of creating a serious game involves various professionals: game designers (responsible for the presence of an element of entertainment in the game), programmers, and experts on the main theme of the game (responsible for the orientation of the game to serious learning objectives). According to Zyda [8], one of the main characteristics of a serious game is to be fun to attract and retain consumer interest.

\section{Means and methods for modeling in the field of serious games focused on learning needs.}

The development of an educational serious game depends on the following factors: target audience, teaching topic and genre of the game. The genre of the game is determined by the challenges the player faces and the actions he takes to overcome them [9]. However, most of the proposed methodologies/frameworks for designing serious games are based on mechanics, dynamics, and experience. The mechanics are related to the official rules of the game, which are directly dependent on the time of the game and are influenced by the player's contribution, forming a dynamic (so-called behavior of the time to play), which creates an experience for the player. The learning content cannot only be related to mechanics, as other mechanisms are needed to support learning content. In his research, the author of [10] presents a methodology for designing and developing serious educational games, based on the concept of learning mechanisms. These mechanisms must be included in the game: storytelling, gameplay, or mechanics.

A scientific study [11] proposed a taxonomy that defines three types of serious games: 1. role-playing games without mandatory simulation of real situations; 2 . business games in which the simulation is like a model of reality; 3 . games simulating reality. 


\section{$3 \quad$ Creating of Serious Games Models for Medical Training}

Education is a process of teaching knowledge and skills from people who have this knowledge to learners who want to acquire it. The use of technology in education is new and still very limited. Especially the use of the game in the classroom is still at the research level. The entry of serious games in medical education, as well as in other educational disciplines, will deepen in the coming years and will become a daily occurrence due to the expansion of the use of smart devices by students [12]. One of the problems that game makers need to work on is to make serious games attractive to their users. The second problem is the combination of the concepts of the game with the concepts of education. The use of the following types of serious games is prevalent in medical education [13, 14, 15]: board games, puzzles, quizzes, strategy games, crosswords games, role-playing games, simulation games, immersive learning environment, virtual learning 3D platform. The authors of [12] define six concepts of the serious game which are used for educational purposes. These concepts are Interactivity, Learning, Scoring, Scenario, Enthusiasm, and User's traces.

A model of a serious game. One of the main problems in the field of serious educational games is the creation of appropriate models of games so that they can meet the needs of the respective educational process. The model must combine pedagogical orientation, ensuring the effectiveness of the game of the respective educational goals and an element of entertainment, ensuring its use by the target group.

The learning model of a serious game should focus on the following events [16]: gaining students' attention; informing users about the purposes of the game; recalling what has already been studied; consolidation of new educational material; availability of clear training guidelines; efficiency of the training process; providing feedback; evaluation of the effectiveness of the use of serious play; improving the means of retaining attention and ensuring quality transfer of new knowledge. Models of design for a serious educational game [17] emphasize the educational pedagogical orientation or the motivational characteristics of the game or integrate these 2 approaches.

In their research $[18,19]$, the authors explore Internet barriers and opportunities to use serious games for students with visual impairments.

Serious games can support the educational process in medicine [20] in 2 ways: by increasing the knowledge and skills of users on a set of topics; by improving students' behavior and reaction through the use of virtual simulation.

\section{$4 \quad$ Video algorithms in Medical Education in Bulgaria}

The video algorithms presented in the article were developed by university professors at the University of Ruse "Angel Kanchev", Faculty of Public Health and Health Care, Department of Health Care Bulgaria [21]. The videos are carefully considered and designed, follow a pre-established methodology for training students in connection with the presented health care manipulation. For better mastering of the practical manipulations in the health care training of nurses and midwives, several video algorithms have been created (algorithm for subcutaneous injection, intravenous 
injection, infusion procedure, intradermal injection, intramuscular injection). Figure 1 to figure 4 show photos from the video algorithm "infusion procedure". As of April 21, 2021 , the presented video algorithm has been viewed a total of 47,599 times (since 16.05.2015), which is an indicator of the interest of users in this educational resource.

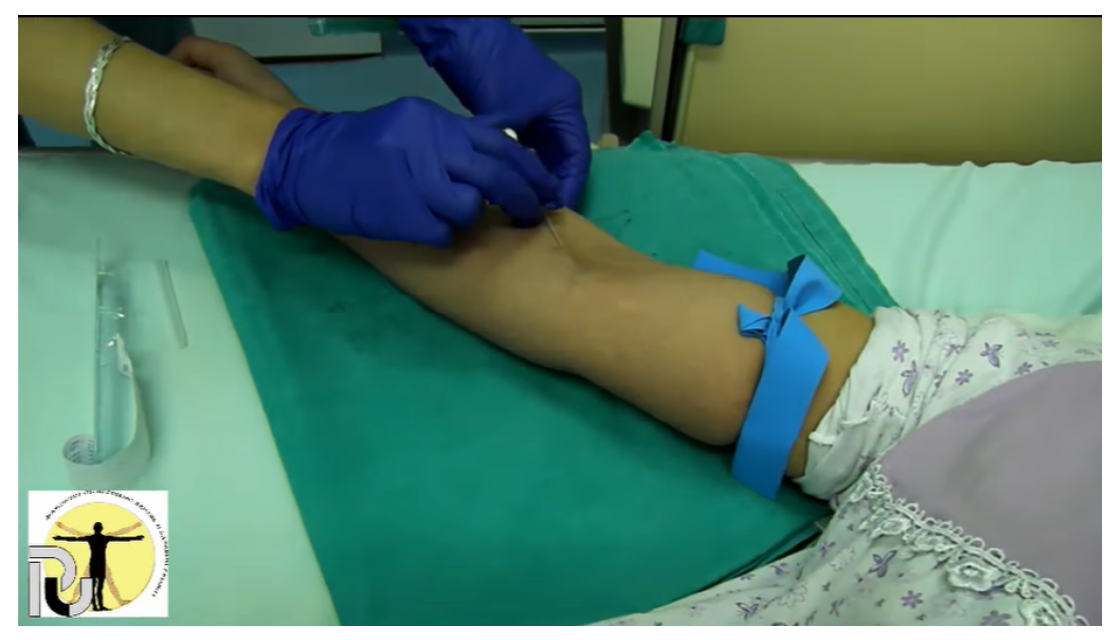

Fig. 1. Tourniquet application and Peripheral Intravenous (IV) Cannulation

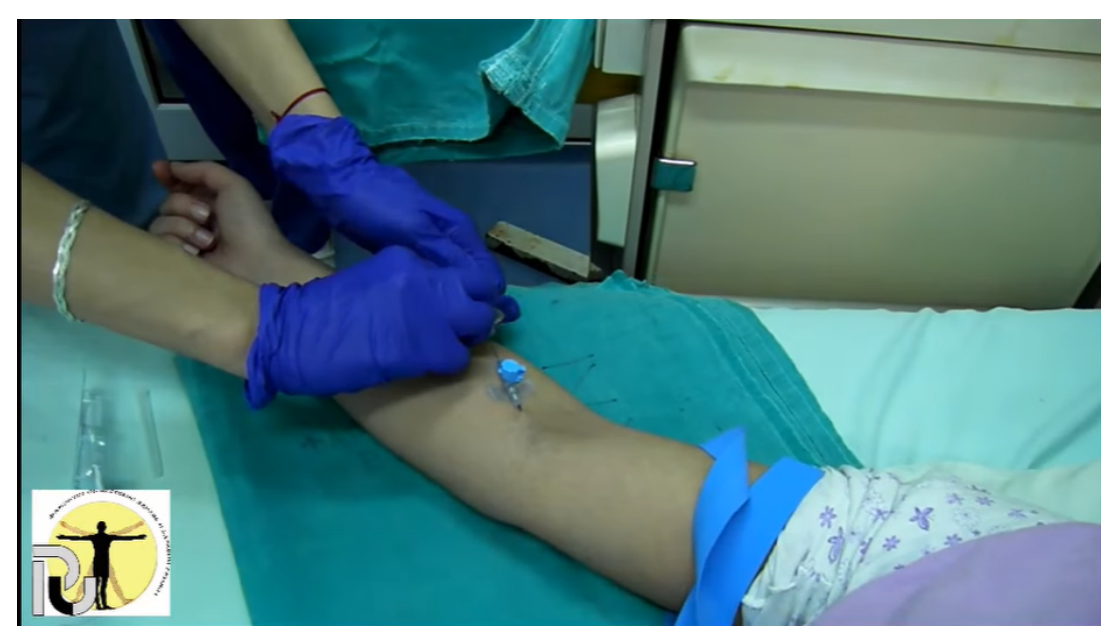

Fig. 2. Carefully remove the needle from the cannula 


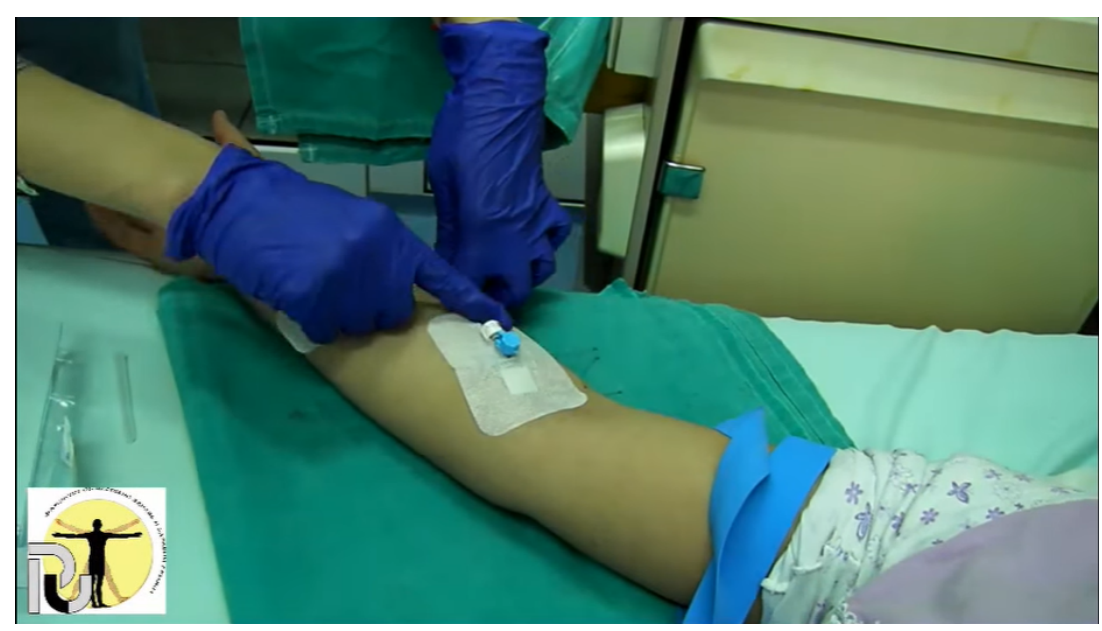

Fig. 3. Fixation of the IV cannula with adhesive tape

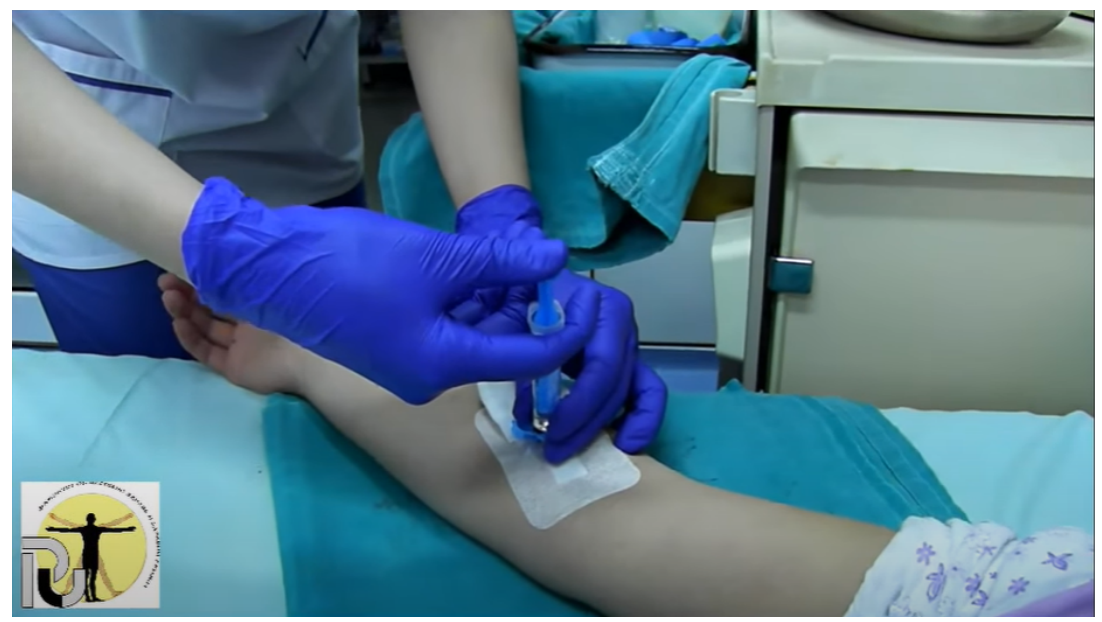

Fig. 4. Chek for patency. Applying the medication/ physiological serum into a vein through an existing IV line

\section{Creating a Medical Educational Game for Nurse and Midwifery Education}

The article presents a serious training game, created to improve the quality of online training and preparation for the exam in the specialties Nurse and Midwife, third course. The main goal of the game is to test students' knowledge in these specialties and give them the opportunity to confirm and improve their knowledge. The Kahoot game-based learning platform is used, which is an educational technology for creating serious games in schools and other educational institutions. Educational games created through 
Kahoot are quizzes with the ability to choose the correct answer. Developed games can be used through the Kahoot application or a web browser. The game presented in the article is a quiz, and in the form of 24 questions, the acquired knowledge is checked. Usually, the correct answer is one of a total of 4 possible answers (Fig. 5 a). The environment also provides an opportunity to give several correct answers to one question. The selected answer lights up in green (Fig. 5 b) if it is correct and in red (Fig. $5 \mathrm{c}$ ) if it is incorrect. The development environment allows you to set the response time for each question (as for each specific question the time may be different). When the response time expires, the game issues an information message (Fig. $5 \mathrm{~d}$ ).

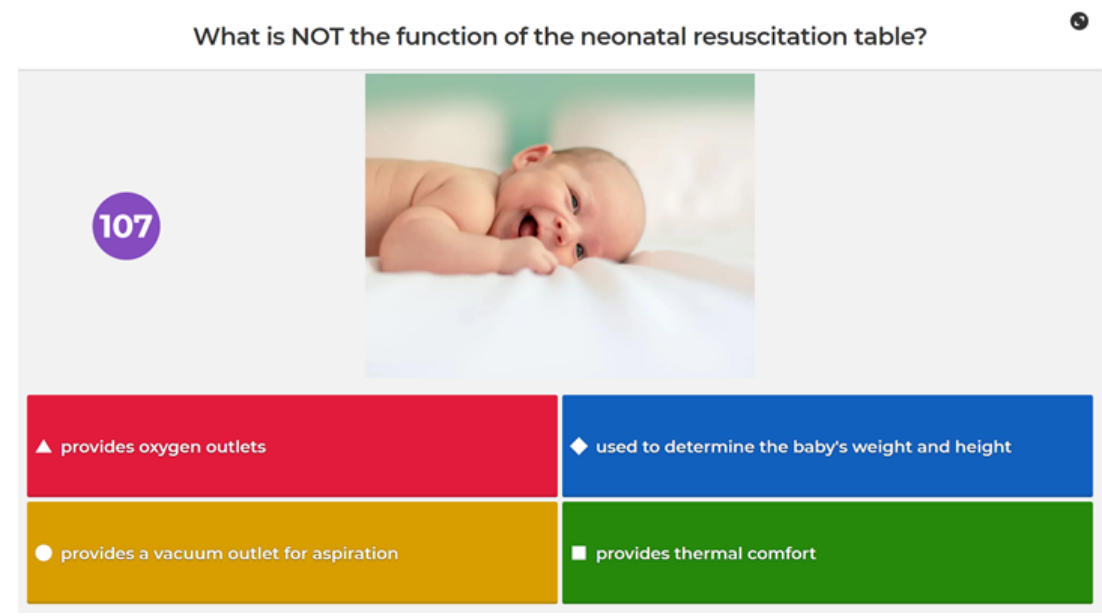

(a)

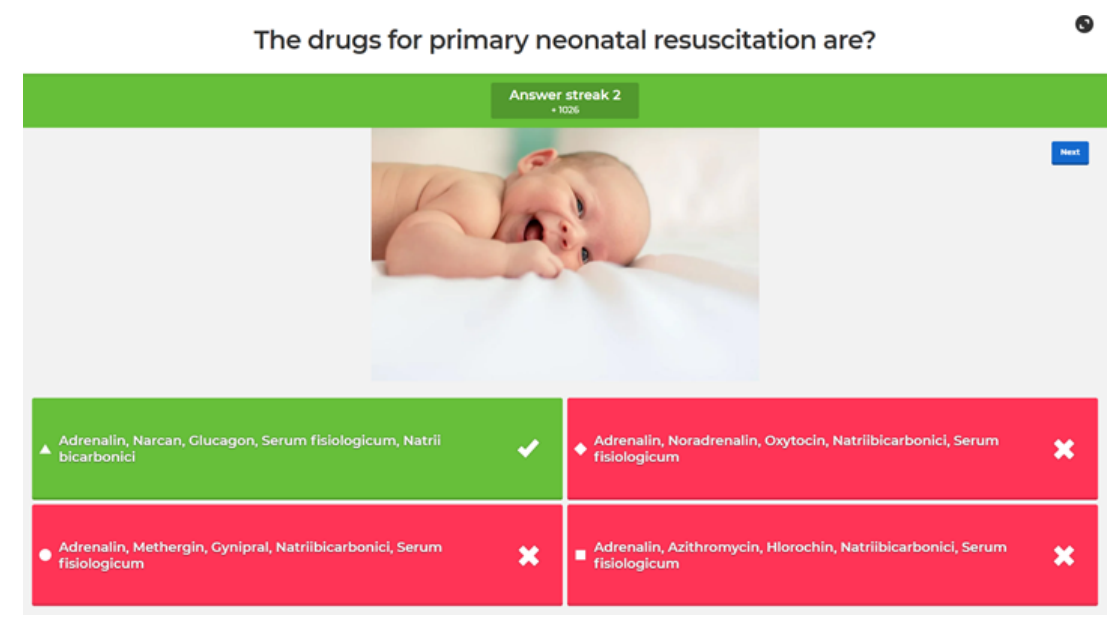

(b) 


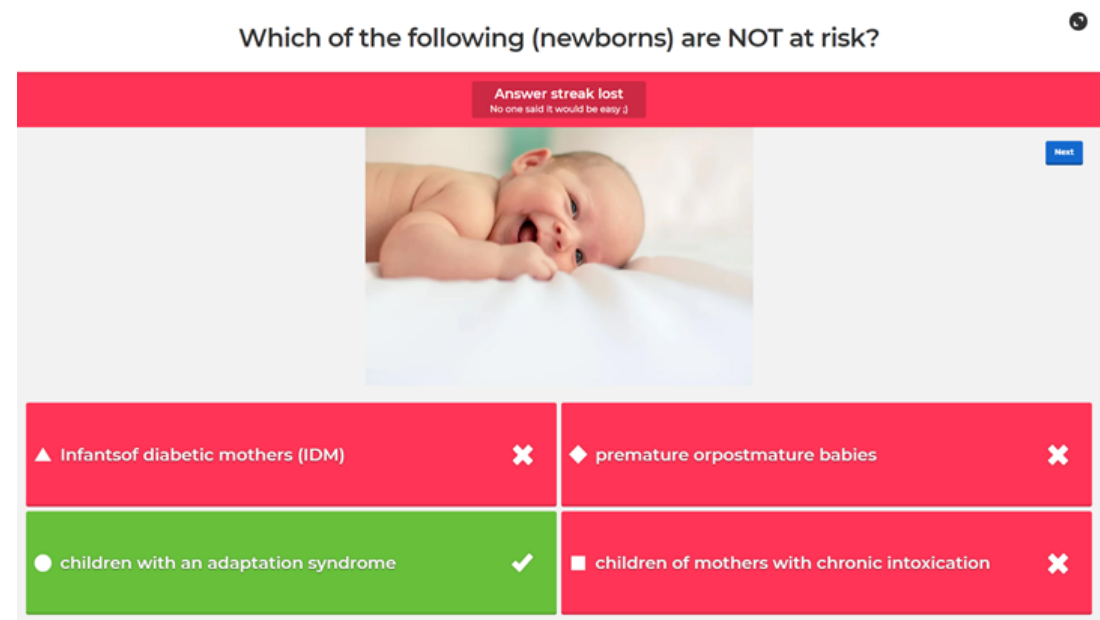

(c)

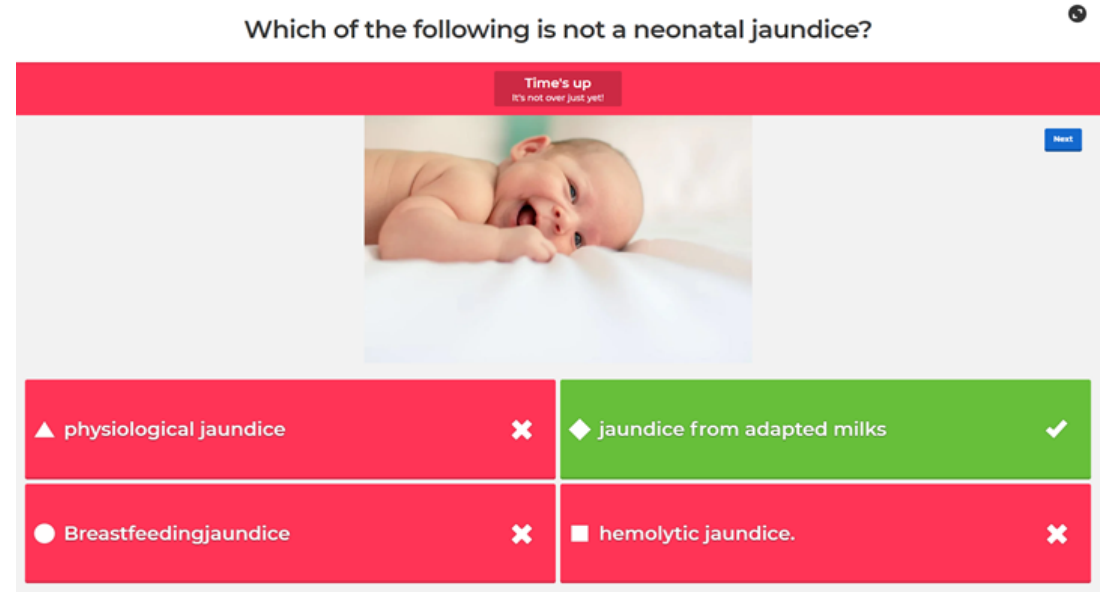

(d)

Fig. 5. Presentation of the training game

The educational game is easy to use by students, does not require special technological skills, can be used on a laptop, computer, mobile phone, interactive whiteboard, and tablet.

The opinion of the students in Bulgaria on the question was studied: what type of serious educational games they prefer to play (Figure 6 - the question allows more than one answer). According to the respondents, the most preferred serious games are those with an element of competition - 72, $8 \%$. 
What type of serious games do you prefer to play?

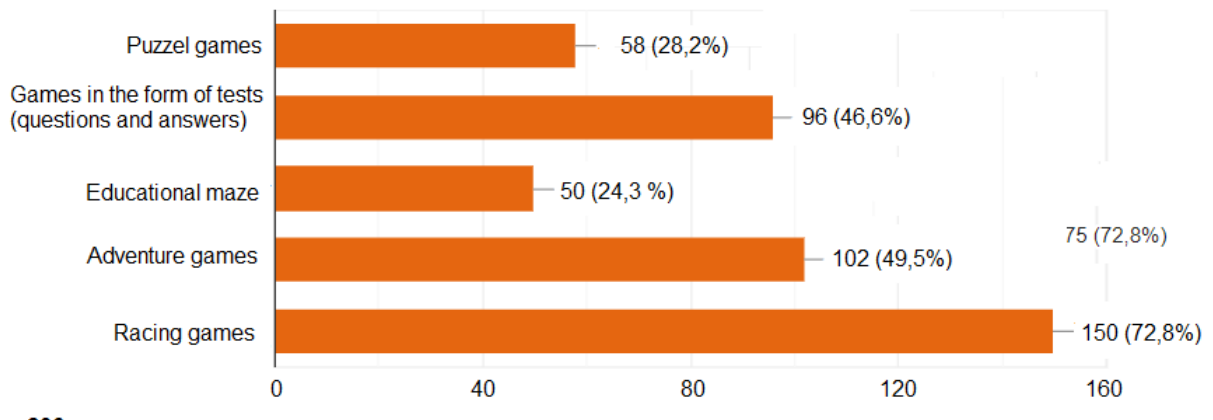

206 answers

Fig. 6. Research on the preferred type of serious game

The results presented in Figure 7 show that the highest percentage of $37.9 \%$ of students use video games for up to 2 hours a day in their free time. The lowest $(2.9 \%)$ is the percentage of gaming users within 5 to 6 hours per day.

How many hours a day do you play video games?
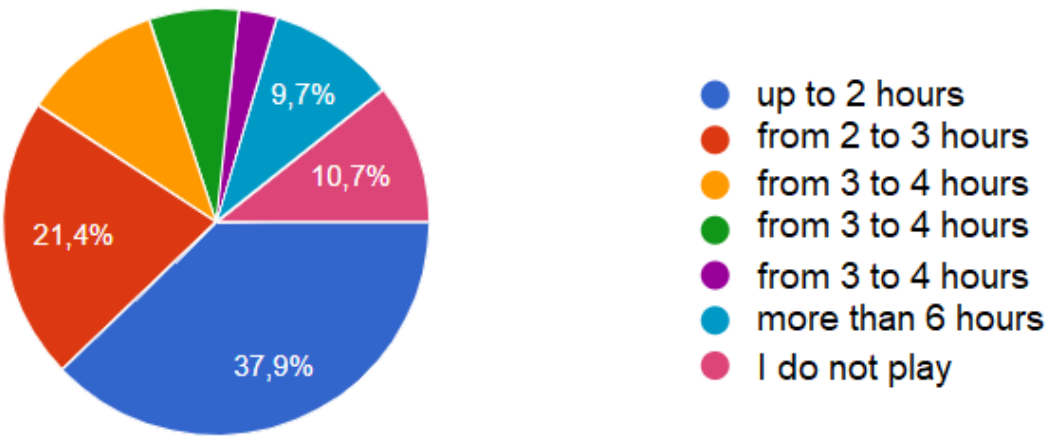

206 answers

Fig. 7. Research on tie spent with video games a day

\section{Conclusion}

The article presents the use of serious educational games in medical education in Bulgaria and especially in the professional field of "Health Care". An important task facing medical educators is to implement the rational integration of SEG in the educational process of future medical and health care professionals. The article presents a medical training game, which aims to increase the knowledge and skills of health care students (specialty "Nurse and Midwife") in preparation for the exam of the third course 
of the nurse in the discipline of special care for children in neonatology, pediatrics. Video material is also presented in the article through which students can consolidate their knowledge and skills in the field of intravenous infusion.

\section{$7 \quad$ Acknowledgment}

This work was supported by the Bulgarian Ministry of Education and Science under the National Research Program - "Young scientists and postdoctoral students" approved by DCM \# $577 / 17.08 .2018$.

\section{$8 \quad$ References}

[1] von der Heiden, J., Braun B., Muller K., Egloff B. (2019). The Association Between Video Gaming and Psychological Functioning. Front. Psychol. https://doi.org/10.3389/fpsyg. 2019.01731

[2] Esposito, N. (2005). A short and simple definition of what a videogame is. In Proceedings of the DiGRA (Digital Games Research Association) Conference: Changing Views-Worlds in Play, (British Columbia: University of Vancouver).

[3] Douvantzis K. (2012). Serious Games - The Future of Learning. http://www.cs.vu.nl/ eliens /serious/local/essay/12/24.pdf. 2012.

[4] Newzoo Global Games Market Report: Trends, Insights, and Projections Toward. (2017). Available at: https://newzoo.com/insights/trend-reports/newzoo-global-games-market-re port-2017-light-version

[5] Adams, E. Fundamentals of Game Design, 3rd ed.; New Riders Games: Berkeley, CA, USA, 2013.

[6] Dimova, M., Paneva-Marinova, D., Pavlova, L. (2018). Towards Better Understanding of Ancient Civilizations by Storytelling and Gaming. TEM Journal, 7 (3), UIKTEN - Association for Information Communication Technology Education and Science, Serbia, ISSN:2217-8309.

[7] Paneva-Marinova, D., Rousseva, M., Dimova, M., Pavlova, L. (2018). Tell the Story of Ancient Thracians through Serious Game. Ioannides M. et al. (eds) Digital Heritage. Progress in Cultural Heritage: Documentation, Preservation, and Protection. EuroMed 2018. October 29th - November 3rd, Cyprus, 11196 LNCS, Lecture Notes in Computer Science (including subseries Lecture Notes in Artificial Intelligence and Lecture Notes in Bioinformatics), 509517. https://doi.org/10.1007/978-3-030-01762-0 44

[8] Zyda M. (2005). From Visual Simulation to Virtual Reality to Games. Computer 38(9): 25 -32. https://doi.org/10.1109/mc.2005.297

[9] Lengyel P., Can the Game-Based Learning Come? Virtual Classroom in Higher Education of 21 st Century. iJET - Vol. 15, No. 2, 112- 126, 2020. https://doi.org/10.3991/ijet.v15i02 .11521

[10] Barbosa A., Pereira P., Dias, J., Silva, F. (2014). A New Methodology of Design and Development of Serious Games. International Journal of Computer Games Technology (2):18. https://doi.org/10.1155/2014/817167

[11] Botte, B., Matera, C., Sponsiello, M. (2009). Serious games between simulation and game: A proposal of taxonomy. J. e-Learn. Knowl. Soc., 5, 11-21.

[12] Darwesh A. (2016). Concepts of Serious Game in Education. International Journal of Engineering and Computer Science, 4 (12), pp. 15229-15232 
[13] C. Kefalis, The Effects of Video Games in Memory and Attention, iJEP - Vol. 10, No. 1, 51-61, 2020. https://doi.org/10.3991/ijep.v10i1.11290

[14] Talib C., Enhancing Students' Reasoning Skills in Engineering and Technology through Game-Based Learning, iJET - Vol. 14, No. 24, 69 - 80, 2019. https://doi.org/10.3991 /ijet.v14i24.12117

[15] Dunne, J., McDonald, C. (2010). Pulse!!: a model for research and development of virtualreality learning in military medical education and training. Military medicine, 175(suppl_7), 25-27. https://doi.org/10.7205/milmed-d-10-00158

[16] Laamarti F., Eid M., Saddik, A. (2014). An Overview of Serious Games. International Journal of Computer Games Technology, Article ID 358152, 15 pages. https://doi.org/10. $1155 / 2014 / 358152$

[17] Braad E., Žavcer G., Sandovar A. (2016). Processes and Models for Serious Game Design and Development. In: Dörner R., Göbel S., Kickmeier-Rust M., Masuch M., Zweig K. (eds) Entertainment Computing and Serious Games. Lecture Notes in Computer Science, vol. 9970. Springer, Cham., pp 92-118. https://doi.org/10.1007/978-3-319-46152-6_5

[18] Noev N., Bogdanova G., Todorov T., Sabev N. (2019). Innovative approach to the presentation of cultural heritage in the game module of serious game for blinded people. Digital Presentation and Preservation of Cultural and Scientific Heritage, 9, 213-218, ISSN 1314-4006 (Print) ISSN 2535-0366 (Online).

[19] Bogdanova G., Sabev N., Noev N. (2019). Accessibility and some educational barriers for visually impaired users. Proc. of the 11th International Technology, Education and Development Conference, Mar 2019, doi: 10.21125/inted.2019.2333, ISBN: 978-84-0908619-1, ISSN: 2340-1079. https://doi.org/10.21125/inted.2019.2333

[20] Georgieva-Tsaneva, G. (2019). Serious Games and Innovative Technologies in Medical Education in Bulgaria. TEM Journal. Volume 8, Issue 4, Pages 1398-1403.

[21] https://www.youtube.com/watch?v=lAP2IVV1hOI

\section{Authors}

Galya Georgieva-Tsaneva, Ph.D. is an Assistant Professor at the Institute of Robotics, Bulgarian Academy of Sciences, Sofia, Bulgaria. Her scientific research interests include serious educational games, web accessibility, medical information system, investigation of Heart Rate Variability of ECG data, wavelet and fractal analysis, coding and compression of information, fractal modeling, computer networks and communications, teletraffic engineering. She is the author/co-author of 3 chapters in scientific books and has published about 90 scientific articles nationally and internationally. She is a member of the Union of Informatics and Automation in Bulgaria, a member of the editorial board of international scientific journals.

Ivanichka Serbezova, Professor, Ph.D. is head of the Department of Education Quality and Accreditation in Ruse University “Angel Kanchev". Master's Degree in Andragogy from Sofia University "St. Kliment Ohridsky" and a Bachelor's Degree in Health Care Management. At the Medical University of Sofia, she acquires her major in Medical Pedagogy. Her research interests include medical education systems, optimizing Healthcare Education, improving the quality of medical education. She is the author of 5 scientific books and has published over 100 scientific articles nationally and internationally. She is a member of the Union of Scientists in Bulgaria, the Bulgarian 
Short Paper-Using Serious Games and Video Materials in Clinical Training in Nursing and Midwifery...

Association of Healthcare Professionals, and the European Public Health Associatio (iserbezova@uni-ruse.bg).

Article submitted 2021-04-21. Resubmitted 2021-05-18. Final acceptance 2021-05-20. Final version published as submitted by the authors. 